\title{
Editorial
}

\section{The global impact on mental health almost 2 years into the COVID-19 pandemic}

\author{
Blanaid Gavin ${ }^{1}$ (1), John Lyne $e^{2,3}$ (1) and Fiona McNicholas ${ }^{4,5}$ (1) \\ ${ }^{1}$ Department of Child and Adolescent Psychiatry, SMMS, University College Dublin, Dublin, Ireland, ${ }^{2}$ Health Service Executive, Wicklow Mental Health Services, \\ Newcastle Hospital, Greystones, Wicklow, Ireland, ${ }^{3}$ Royal College of Surgeons in Ireland, Dublin, Ireland, ${ }^{4}$ Children Health Ireland, Dublin, Ireland and ${ }^{5}$ Lucena \\ Clinic Rathgar, Dublin, Ireland
}

\begin{abstract}
Approaching 2 years into a global pandemic, it is timely to reflect on how COVID-19 has impacted the mental health of the global population. With research continuing apace, a clearer picture should crystallise in time. COVID-19 has undoubtedly had some impact on population mental health, although the severity and duration of this impact remain less clear. The exceptional period of COVID-19 has provided a unique prism through which we can observe and consider societal mental health. This is a momentous time to be involved in mental health research as we strive to understand the mental health needs of the population and advocate for adequate resourcing to deliver quality mental healthcare in the post-pandemic period.
\end{abstract}

COVID-19; global mental health; mental health; mental illness

(Received 14 October 2021; accepted 29 October 2021)

\section{Introduction}

COVID-19 has been the most seismic public health event in living memory with reverberations globally across all strata of society necessitating unprecedented governmental interventions which have altered daily living. In the early aftermath of the WHO declaring a global pandemic in March 2020, there was an awareness that the impact of the pandemic and the measures necessary to curtail it, would inevitably result in psychological morbidity (Holmes et al. 2020; Hotopf et al. 2020). While the focus at the outset of the pandemic was understandably sharply focused on physical illness, the likely mental health implications were also highlighted at a very early stage with calls for appropriate measures to offset this risk (O’Connor et al. 2021). Data from previous major emergencies and pandemics pointed to a likely peak in mental health problems which was predicted to occur later than the initial peak in physical illness, and also to endure for longer (NATO Joint Medical Committee 2008; Shultz et al. 2013; Health Service Executive, 2014). Similarly at a very early stage in the pandemic, based on evidence from previous epidemics such as the severe acute respiratory syndrome (SARS) virus, it was postulated that particular groups were likely to face higher rates of negative mental health outcomes for a variety of reasons (Cheung et al. 2008; Cheung et al. 2010; Mak et al. 2009; Lee et al. 2018; Gao et al. 2020; Rogers et al. 2020). These included healthcare workers, those with pre-existing mental illness, the youth population and individuals experiencing socio-economic adversity. It was also anticipated that pre-pandemic

Address for correspondence: J. Lyne, Wicklow Mental Health Services, Newcastle Hospital, Greystones, Wicklow, Ireland. (Email: johnlyne@rcsi.ie)

Cite this article: Gavin B, Lyne J, and McNicholas F. (2021) The global impact on mental health almost 2 years into the COVID-19 pandemic. Irish Journal of Psychological Medicine 38: 243-246, https://doi.org/10.1017/ipm.2021.75 inequalities and associated mental health risk would be increased by the pandemic and its aftermath (O'Connor et al. 2020).

Approaching 2 years into this pandemic efforts continue to clarify how this unique event has impacted the global population. Research into the evolving societal impact and mental health consequences remain at an early stage as the global population continues to cycle through various stages of psychological response and adaptation. As such the pandemic remains a dynamic global psychosocial stressor. The evidence in relation to neuropsychiatric impact also continues to evolve as COVID-19 inflammatory responses, neurotropism and iatrogenic effects can change at different points of illness and recovery. The potential for distinct neuropsychiatric consequences with emerging variants remains uncertain. Furthermore, the impact of long COVID on psychological well-being and rates of mental illness needs further consideration (Berenguera et al. 2021). Without doubt, it is injudicious to draw definitive conclusions on a process which is ongoing. Notwithstanding the fact that much remains to be learned, it seems timely to reflect on what is now known about the impact of the pandemic on population mental health and how this is likely to shape prevalence of mental illness and service needs in the short and long term. Moreover, the pandemic provides a useful prism through which to consider contemporary views of mental illness and service provision.

\section{Mental health and societal impacts of COVID-19}

Measuring the impact of COVID-19 on population mental health poses significant challenges (Patten et al. 2021). While numerous studies have reported increase in psychiatric morbidity since onset of COVID-19, in particular for population levels of depression and anxiety (COVID-19 Mental Disorders Collaborators, 2021; 
Thorisdottir et al. 2021; Santabárbara et al. 2021; Fancourt et al. 2021; Pierce et al. 2020; Samji et al. 2021), some studies have also suggested the possibility that the overall effect on population mental health was moderate (Hafstad et al. 2021; Sharp et al. 2021; Knudsen et al. 2021; Nichter et al. 2021; John et al. 2020). Several of these studies suggest greater mental health issues among those diagnosed with COVID-19 and perhaps among certain population cohorts such as the youth population. However, interpretation of the findings is complicated by the possibility of variation in population mental distress at different phases of the pandemic and in particular with respect to the lockdown restrictions imposed at different phases.

The impact of the pandemic on referrals and presentations has also varied across pandemic phases, with some empirical research suggesting a delayed surge in psychiatric referrals to both adult (McIntyre et al. 2021) and paediatric emergency departments (McDonnell et al. 2021). Studies have suggested that tertiary mental health services have experienced a delayed but significant increase in both routine and urgent referrals to Child and Adolescent Mental Health Services, with one study demonstrating substantial increases from September 2020 post-COVID-19 when compared with pre-pandemic years (McNicholas et al. 2021).

The pandemic management strategies, such as lockdown restrictions, employed by many governments globally have required myriad shifts in population behaviours, which may have negatively impacted certain vulnerable populations more than others. Numerous examples of negative consequences exist, such as dramatically increased rates of domestic violence, the deleterious impact of school closures for vulnerable children (Kofman \& Garfin, 2020), and concerns about the impact of punitive restriction regimens on the elderly, especially by way of increased social isolation and loneliness (Van Tilburg et al. 2021). Debates have ensued as to the rationale and evidence base for the restrictions imposed and the unintended, unforeseen consequences of these restrictions (Boettke \& Powell, 2021). While the need for a nuanced approach for certain populations in society is evident, the feasibility of enacting in real-time, a population level pandemic response catering to the particular needs of multiple different vulnerable groups, is a uniquely challenging task for all governments.

\section{Delivering healthcare for severe and enduring mental illness}

One consequence of the enforced changes to people's daily lives is that arguably there has never been more societal and media focus on 'mental health'. However, in keeping with the trajectory of this discourse pre-pandemic it appears reasonable to assert that this increased awareness of 'mental health' is not translating as effectively into increased awareness of severe 'mental illness', and by extension the serious implications of the pandemic for those with severe mental illness. Against this backdrop, caution was urged early in the pandemic as to the danger of an over-focus in epidemiological research on the psychological needs of milder psychological distress, instead of concentrating more efforts on vulnerable groups at higher risk of severe and enduring psychological morbidity (Danese \& Smith, 2020). An emphasis on delivering resources for severe and enduring mental illness is crucial in the post-pandemic period as this population will continue to endure mental health difficulties in the longer term.

A number of authors have noted the bidirectional link between COVID-19 and mental illness; COVID-19 elevates risk of mental illness and mental illness elevates the risks of COVID-19 (Taquet et al. 2021; Wang et al. 2021). A recent meta-analysis has robustly demonstrated that pre-existing mood disorders are associated with higher rates of hospitalisation and death from COVID-19 infection (Ceban et al. 2021). Additionally, individuals with mental illness requiring inpatient or residential care, by virtue of congregated living and difficulty in adherence to risk mitigation strategies can be at increased risk of exposure and transmission of COVID-19 (Kozloff et al. 2020). The authors argue that mental health disorders should be recognised as a high-risk condition similar to other pre-existing conditions such as obesity; however, this has not been adequately recognised in delivering COVID-19 risk categorisation and vaccine access for those with mental illness. The inclusion of mental illnesses in the algorithms employed to characterise COVID-19 risk levels is fundamentally important to a society which aims to provide parity of health services for those with physical or mental illness and by extension parity of resourcing and safety in the workplace for healthcare workers in the physical and mental healthcare domain.

\section{Impact of COVID-19 on healthcare workers}

Concerns were also voiced from the outset of the pandemic as to the likely impact of the pandemic on the psychological well-being of healthcare workers (Greenberg et al. 2020). This was based on the noted increase in psychological morbidity associated with healthcare workers in previous epidemics, most notably SARS (Maunder, 2004, 2008; Preti et al., 2020). While much of the research on the psychological fallout emanating from the pandemic has focused on frontline acute hospital settings, emerging data suggests that many of the psychological stressors, such as fears of illness, staff shortages, lack of personal protective equipment were also present across other non-frontline healthcare settings (Billings et al. 2021). Furthermore, while research has indicated elevated levels of psychological morbidity in frontline hospital workers (De Kock et al. 2021), it is also evident that morbidity has been significant among other healthcare workers.

The additional stress of introducing urgent systems change across the healthcare system cannot go unrecognised. For example, many community-based healthcare workers were required to introduce very significant changes in models of care provision such as providing interventions virtually. It has been hypothesised that pandemic preparedness, a known protective factor relating to postpandemic psychological morbidity, may have been better in acute hospital settings leading to greater resilience among staff in these settings (Li et al. 2020). Another area of growing concern is that a possible over-focus on individual rather than systemic factors relating to psychological morbidity in healthcare workers may inappropriately result in resourcing of interventions focused on enhancing individual resilience as opposed to resourcing a system which reduces burnout by optimising effective working.

\section{Mental health service resourcing for the post-pandemic period}

In anticipation of continued increased demand on specialist mental health services, increased resourcing is essential if meaningful progress is to be achieved in providing adequate psychiatric services in line with post-pandemic need (COVID-19 Mental Disorders Collaborators, 2021). Undoubtedly this pandemic has provided an opportunity for increased awareness of mental illness and has highlighted the need for delivering appropriate resources. The arbitrary distribution of mental health funding without an evidence-based approach remains a concern in many jurisdictions. 
However, despite these well-founded concerns, cause for optimism should remain. Utilisation of post-disaster recovery approaches such as developed by the UN in 'Build Back Better' can enhance societal resilience by utilising multi-layered actions in the short and longer term to optimise outcomes (United Nations General Assembly, 2016). The paradigm of 'Build Back Better' has resonance for mental health services with calls for policymakers to seize the opportunities presented by the pandemic (Hoagwood \& Kelleher, 2020). Given the groundswell of grassroots support for increased funding for mental health services together with the evident desire across all sectors for improved service provision, the time has arrived to ensure the unique opportunities presented by this pandemic can translate advocacy to resourcing, ensuring actionable outputs are delivered for better mental health services (Latoo et al. 2021).

Financial support. This article received no specific grant from any funding agency, commercial or not-for-profit sectors.

Conflict of interest. BG has no conflicts of interest to disclose. JL has no conflicts of interest to disclose. FMcN has no conflicts of interest to disclose.

Ethical standards. The author asserts that all procedures contributing to this work comply with the ethical standards of the relevant national and institutional committee on human experimentation with the Helsinki Declaration of 1975, as revised in 2008.

\section{References}

Berenguera A, Jacques-Aviñó C, Medina-Perucha L, Puente D (2021). Long term consequences of COVID-19. European Journal of Internal Medicine $\mathbf{9 2}$, 34-35 DOI 10.1016/j.ejim.2021.08.022.

Billings J, Biggs C, Ching BCF, Gkofa V, Singleton D, Bloomfield M, Greene T (2021). Experiences of mental health professionals supporting front-line health and social care workers during COVID-19: qualitative study. BJPsych Open 7, e70.

Boettke P, Powell B (2021). The political economy of the COVID-19 pandemic. Southern Economic Journal 87, 1090-1106 DOI 10.1002/soej. 12488.

Ceban F, Nogo D, Carvalho IP, et al. (2021). Association between mood disorders and risk of COVID-19 infection, hospitalization, and death: a systematic review and meta-analysis. JAMA Psychiatry 78, 1079 DOI 10.1001/ jamapsychiatry.2021.1818.

Cheung YT, Chau PH, Law YW (2010). The impact of epidemic outbreak the case of Severe Acute Respiratory Syndrome (SARS) and suicide among older adults in Hong Kong. Crisis 31, 86-92.

Cheung YT, Chau PH, Yip PSF (2008). A revisit on older adults suicides and severe acute respiratory syndrome (SARS) epidemic in Hong Kong. International Journal of Geriatric Psychiatry 23, 1231-1238.

COVID-19 Mental Disorders Collaborators (2021). Global prevalence and burden of depressive and anxiety disorders in 204 countries and territories in 2020 due to the COVID-19 pandemic. Lancet 398, 1700-1712 DOI 10. 1016/S0140-6736(21)02143-7.

Danese A, Smith P (2020). Debate: recognising and responding to the mental health needs of young people in the era of COVID-19. Child and Adolescent Mental Health 25, 169-170 DOI 10.1111/camh.12414.

De Kock JH, Latham HA, Leslie SJ, Grindle M, Munoz S-A, Ellis L, Polson R, O'Malley CM (2021). A rapid review of the impact of COVID-19 on the mental health of healthcare workers: implications for supporting psychological well-being. BMC Public Health 21, 104.

Fancourt D, Steptoe A, Bu F (2021). Trajectories of anxiety and depressive symptoms during enforced isolation due to COVID-19 in England: a longitudinal observational study. The Lancet Psychiatry 8, 141-149 DOI 10.1016/ S2215-0366(20)30482-X.

Gao J, Zheng P, Jia Y, Chen H, Mao Y, Chen S, et al. (2020). Mental health problems and social media exposure during COVID-19 outbreak. PLoS One 15, e0231924.
Greenberg N, Docherty M, Gnanapragasam S, Wessely S (2020). Managing mental health challenges faced by healthcare workers during covid-19 pandemic. BMJ 368, m1211 DOI 10.1136/bmj.m1211.

Hafstad GS, Sætren SS, Wentzel-Larsen T, Augusti EM (2021). Adolescents' symptoms of anxiety and depression before and during the Covid-19 outbreak - a prospective population-based study of teenagers in Norway. The Lancet Regional Health - Europe 5, 100093 DOI 10.1016/j.lanepe.2021.100093.

Health Service Executive (2014). National Vision for Change Working Group, Psychosocial \& Mental Health Needs Following Major Emergencies. A Guidance Document.

Hoagwood KE, Kelleher KJ (2020). A marshall plan for children's mental health after COVID-19. Psychiatric Services 71, 1216-1217 DOI 10.1176/ appi.ps.202000258.

Holmes EA, O'Connor RC, Perry VH, Tracey I, Wessely S, Arseneault L, et al. (2020). Multidisciplinary research priorities for the COVID-19 pandemic: a call for action for mental health science. The Lancet Psychiatry 7 , $547-560$.

Hotopf M, Bullmore E, O'Connor RC, Holmes EA (2020). The scope of mental health research during the COVID-19 pandemic and its aftermath. The British Journal of Psychiatry 217, 540-542.

John A, Eyles E, Webb RT, Okolie C, Schmidt L, Arensman E, Hawton K, O'Connor RC, Kapur N, Moran P, O'Neill S, McGuiness LA, Olorisade BK, Dekel D, Macleod-Hall C, Cheng HY, Higgins JPT, Gunnell D (2020). The impact of the COVID-19 pandemic on self-harm and suicidal behaviour: update of living systematic review. F1000Res 9, 1097 DOI 10. 12688/f1000research.25522.2.

Knudsen AKS, Stene-Larsen K, Gustavson K, Hotopf M, Kessler RC, Krokstad S, Skogen JC, Øverland S, Reneflot A (2021). Prevalence of mental disorders, suicidal ideation and suicides in the general population before and during the COVID-19 pandemic in Norway: a population-based repeated cross-sectional analysis. The Lancet Regional Health - Europe 4, 100071 DOI 10.1016/j.lanepe.2021.100071.

Kofman YB, Garfin DR (2020). Home is not always a haven: the domestic violence crisis amid the COVID-19 pandemic. Psychological Trauma 12, S199-S201.

Kozloff N, Mulsant BH, Stergiopoulos V, Voineskos AN (2020). The COVID19 global pandemic: implications for people with schizophrenia and related disorders. Schizophrenia Bulletin 46, 752-757.

Latoo J, Haddad PM, Mistry M, Wadoo O, Islam SMS, Jan F, Iqbal Y, Howseman T, Riley D, Alabdulla M (2021). The COVID-19 pandemic: an opportunity to make mental health a higher public health priority. BJPsych Open 7, el72 DOI 10.1192/bjo.2021.1002.PMID:.

Lee SM, Kang WS, Cho A-R, Kim T, Park JK (2018). Psychological impact of the 2015 MERS outbreak on hospital workers and quarantined hemodialysis patients. Comprehensive Psychiatry 87, 123-127.

Li Z, Jingwu G, Meiling Y, Jianping F, Mei Q, Riyue J, et al. (2020). Vicarious traumatization in the general public, members, and non-members of medical teams aiding in COVID-19 control. Brain, Behavior, and Immunity 88, 916-919.

Mak IWC, Chu CM, Pan PC, Yiu MGC, Chan VL (2009). Long-term psychiatric morbidities among SARS survivors. General Hospital Psychiatry 31, 318-326.

Maunder RG, Leszcz M, Savage D, Adam MA, Peladeau N, Romano D, Rose M, Schulman RB (2008). Applying the lessons of SARS to pandemic influenza: an evidence-based approach to mitigating the stress experienced by healthcare workers. Canadian Journal of Public Health 99, 486-488 DOI $10.1007 / \mathrm{bf} 03403782$.

Maunder R, Maunder R (2004). The experience of the 2003 SARS outbreak as a traumatic stress among frontline healthcare workers in Toronto: lessons learned. Philosophical Transactions. Biological Sciences 359, 1117-1125 DOI 10.1098/rstb.2004.1483.

McDonnell T, Barrett M, McNicholas F, Barrett E, Conlon C, Cummins F, Hensey C, McAuliffe E, Nicholson E (2021). Increased mental health presentations by children aged 5-15 at emergency departments during the first 12 months of COVID-19. Irish Medical Journal 114, 356.

McIntyre A, Tong K, McMahon E, Doherty AM (2021). COVID-19 and its effect on emergency presentations to a tertiary hospital with self-harm in Ireland. Irish Journal of Psychological Medicine 38, 116-122. 
McNicholas F, Kelleher I, Hedderman E, Lynch F, Healy E, Thornton T, Barry E, Kelly L, McDonald J, Holmes K, Kavanagh G (2021). Referral patterns for specialist child and adolescent mental health services in the Republic of Ireland during the COVID-19 pandemic compared with 2019 and 2018. BJPsych Open 7, e91.

Nichter B, Hill ML, Na PJ, Kline AC, Norman SB, Krystal JH, Southwick SM, Pietrzak RH (2021). Prevalence and trends in suicidal behavior among US military veterans during the COVID-19 pandemic. JAMA Psychiatry 25, e212332 DOI 10.1001/jamapsychiatry.2021.2332.

North Atlantic Treaty Organisation (NATO) (2008). Psychosocial Care for People Affected by Disasters and Major Incidents: a model for designing, delivering, and managing psychosocial services for people involved in major incidents, conflict, disasters and terrorism. NATO (https://www.coe.int/t/ dg4/majorhazards/ressources/virtuallibrary/materials/Others/NAT_Guidance_ Psychosocial_Care_for_People_Affected_by_Disasters_and_Major_Incidents. pdf).

O'Connor RC, Wetherall K, Cleare S, McClelland H, Melson AJ, Niedzwiedz CL, O'Carroll RE, O'Connor DB, Platt S, Scowcroft E, Watson B, Zortea T, Ferguson E, Robb KA (2020). Mental health and well-being during the COVID-19 pandemic: longitudinal analyses of adults in the UK COVID-19 mental health \& wellbeing study. British Journal of Psychiatry 218, 1-333 DOI 10.1192/bjp.2020.212.

O'Connor K, Wrigley M, Jennings R, Hill M, Niazi A (2021). Mental health impacts of COVID-19 in Ireland and the need for a secondary care mental health service response. Irish Journal of Psychological Medicine 38, 99-107 DOI 10.1017/ipm.2020.64.

Patten SB, Kutcher S, Streiner D, Gratzer D, Kurdyak P, Yatham L (2021). Population mental health and COVID-19: why do we know so little? The Canadian Journal of Psychiatry 66, 782-784 DOI 10.1177/ 07067437211010523.

Pierce M, Hope H, Ford T, Hatch S, Hotopf M, John A, Kontopantelis E, Webb R, Wessely S, McManus S, Abel KM (2020). Mental health before and during the COVID-19 pandemic: a longitudinal probability sample survey of the UK population. The Lancet Psychiatry 7, 883-892 DOI 10.1016/ S2215-0366(20)30308-4.

Preti E, Di Mattei V, Perego G, et al. (2020). The psychological impact of epidemic and pandemic outbreaks on healthcare workers: rapid review of the evidence. Current Psychiatry Reports 22, 43 DOI 10.1007/s11920-02001166-z.

Rogers JP, Chesney E, Oliver D, Pollak TA, McGuire P, Fusar-Poli P, et al. (2020). Psychiatric and neuropsychiatric presentations associated with severe coronavirus infections: a systematic review and meta-analysis with comparison to the COVID-19 pandemic. The Lancet Psychiatry 7, 611-627.

Samji H, Wu J, Ladak A, Vossen C, Stewart E, Dove N, Long D, Snell G (2021). Review: Mental health impacts of the COVID-19 pandemic on children and youth - a systematic review. Child and Adolescent Mental Health. DOI 10.1111/camh.12501.

Santabárbara J, Lasheras I, Lipnicki DM, Bueno-Notivol J, Pérez-Moreno M, López-Antón R, De la Cámara C, Lobo A, Gracia-García P (2021) Prevalence of anxiety in the COVID-19 pandemic: an updated meta-analysis of community-based studies. Progress in Neuro-Psychopharmacology \& Biological Psychiatry 109, 110207 DOI 10.1016/j.pnpbp.2020.110207.

Sharp ML, Serfioti D, Jones M, Burdett H, Pernet D, Hull L, Murphy D, Wessely S, Fear NT (2021). UK veterans' mental health and well-being before and during the COVID-19 pandemic: a longitudinal cohort study. BMJ Open 11, e049815 DOI 10.1136/bmjopen-2021-049815.

Shultz JM, Neria Y, Allen A, Espinel Z (2013). Psychological impacts of natural disasters. In Encyclopedia of Natural Hazards (ed. P Bobrowsky), pp. 779-791. Springer Publishing: Dordrecht, Heidelberg, London, New York.

Taquet M, Luciano S, Geddes JR, Harrison PJ (2021). Bidirectional associations between COVID-19 and psychiatric disorder: retrospective cohort studies of 62354 COVID-19 cases in the USA. The Lancet Psychiatry 8, $130-140$.

Thorisdottir IE, Asgeirsdottir BB, Kristjansson AL, Valdimarsdottir HB, Jonsdottir Tolgyes EM, Sigfusson J, Allegrante JP, Sigfusdottir ID, Halldorsdottir T (2021). Depressive symptoms, mental wellbeing, and substance use among adolescents before and during the COVID-19 pandemic in Iceland: a longitudinal, population-based study. The Lancet Psychiatry 8, 663-672 DOI 10.1016/S2215-0366(21)00156-5.

United Nations General Assembly (2016). Report of the Open-Ended Intergovernmental Expert Working Group on Indicators and Terminology Relating to Disaster Risk Reduction. United Nations General Assembly: Geneva, https://www.preventionweb.net/files/50683_oiewgreportenglish.pdf.

Van Tilburg TG, Steinmetz S, Stolte E, van der Roest H, de Vries DH (2021). Loneliness and mental health during the COVID-19 pandemic: a study among Dutch older adults. The Journals of Gerontology: Series B 76, e249-e255.

Wang Q, Xu R, Volkow ND (2021). Increased risk of COVID-19 infection and mortality in people with mental disorders: analysis from electronic health records in the United States. World Psychiatry 20, 124-130. 